\title{
COLONOSCOPY COMPLICATIONS IN THE ELDERLY: the impact of age and multimorbidity
}

\author{
Francine de Cristo STEIN1, Naira Hossepian Salles de Lima HOJAIJ1, \\ Jose Guilherme Nogueira da SILVA22, Luana Vilarinho BORGES², \\ Wilson JACOB-FILHO ${ }^{1}$ and Claudio Lyoiti HASHIMOTO²
}

\begin{abstract}
Context - Age has been considered an independent risk factor for colonoscopy complications, especially when associated with multimorbidity. Objectives - The primary objective was to verify the relationships between age, multimorbidity and colonoscopy complications in the elderly. Methods - A retrospective cohort including patients of 60 years or older who had undergone a colonoscopy. Data relating to age, multimorbidities according to the cumulative illness scale for geriatrics and the Charlson index and complications related to bowel preparation and procedure (sedation and exam) were collected. Results - Of the 207 patients (mean age $70.47 \pm 7.04$ ) with appropriate indication for colonoscopy according to the American Society for Gastrointestinal Endoscopy, 43 (20.77\%) patients had some colonoscopy complications: $1(0.48 \%)$ with the sedation (apnea), $4(1.93 \%)$ with the procedure (abdominal pain and bacteremia) and $38(18.35 \%$ ) with the bowel preparation (acute renal failure, hypotension). Individuals $\geq 80$ years had an $\mathrm{RR}=3.4(1.2-10.1), P=0.025$, and those with a Charlson index 3 had an $\mathrm{RR}=5.2(1.6-16.8), P=0.006$, for complications. The cumulative illness rating scale for geriatrics was not associated with complications $(P=0.45)$. Conclusion - There was a significant risk of complications in $\geq 80$ years and in the group with a Charlson index 3 . The cumulative illness rating scale for geriatrics was not a good predictor of risk in this sample.
\end{abstract}

HEADINGS - Colonoscopy, adverse effects. Aged. Morbidity.

\section{INTRODUCTION}

Colorectal cancer (CRC) is the third most prevalent cancer in the world, for both genders. In Brazil there were an estimated 14,180 cases in men and 15,960 cases in women for the year 2012, which corresponds to a relative risk of 15:100,000 for men and 16:100,000 for women ${ }^{(10)}$. Age is an important risk factor for CRC, as the incidence doubles every decade, from 40 to 80 years of age ${ }^{(20)}$.

Currently, the gold standard method for evaluation of the colon and rectum is a colonoscopy ${ }^{(13)}$. A recent cohort study has demonstrated a $53 \%$ reduction in mortality from colorectal cancer, after a period of 15.8 years, in patients submitted to colonoscopic polypectomy ${ }^{(23)}$. However, despite its high accuracy, colonoscopy is not a simple procedure without risk ${ }^{(5,6)}$. The complication rate is variable, ranging from $0.1 \%$ to $0.5 \%$ in studies on individuals over 40 years ${ }^{(11)}$ and from $0.9 \%$ to $16 \%$ in individuals aged 70 years and older ${ }^{(11,24)}$.

Colonoscopy complications may be due to bowel preparation, sedation and the procedure itself, in- cluding: abdominal discomfort, nausea, vomiting, dehydration, electrolyte disturbances, cardiac arrhythmias, hypotension, bleeding, perforation and death $^{(6,11)}$. Age has been considered an independent risk factor for such complications ${ }^{(6,15)}$, especially when in conjunction with multiple diseases ${ }^{(5)}$. This situation most often arises with advancing age and may be one of the factors responsible for differences in diagnosis, treatment and complications in this population.

Comorbidity was defined by Feinstein as "any additional clinical condition that exists or that could occur during the clinical course of a patient who had the disease under study"(8). Multimorbidity is another term frequently found in medical literature as a synonym of comorbidity. Van den Akker et al. define this term differently as "the simultaneous occurrence of two or more chronic diseases in the same individual"(21). In the present study the second terminology will be used in order to bring a broader dimension to this phenomenon.

Some authors have suggested scales that could rate multimorbidity more objectively. The Charlson Index

Declared conflict of interest of all authors: none

Departamento de Geriatria, Hospital das Clínicas da Faculdade de Medicina da Universidade de São Paulo (HC - FMUSP), São Paulo, SP, Brasil; ${ }^{2}$ Departamento de Gastroenterologia da Faculdade de Medicina da Universidade de São Paulo (FMUSP), São Paulo, SP, Brasil.

Correspondence: Francine de Cristo Stein. Hospital das Clínicas da Faculdade de Medicina da Universidade de São Paulo. Av. Dr. Enéas de Carvalho Aguiar, 155, 8 andar - 05409-011 - São Paulo, SP, Brasil. Email: francinecstein@gmail.com 
is one of the most frequently used for objective measurement of multimorbidity, evaluating the presence of 19 medical conditions and assigning each a score of 1 to 6 , based on their risk of death at 1 year ${ }^{(2)}$. In practice it demonstrates a good relationship with mortality and has been a good index to assess multimorbidity in oncologic patients, as well as in clinical research ${ }^{(4,6)}$. Another index used to predict mortality is the "The cumulative illness rating scale for geriatrics" (CIRS-G). This scale quantifies and determines the severity of the chronic medical illness burden by means of scores involving different anatomical sites ${ }^{(14,16)}$.

The primary objective of this study was to verify the relationship between age, multimorbidity and colonoscopy complications in an elderly population. The second objective was to determine how often colonoscopy complications occur within 30 days of the procedure, in this population.

\section{METHODS}

Outpatients and inpatients undergoing elective colonoscopy were evaluated in this observational, retrospective and longitudinal study, performed from January 2006 to December 2006, in a single-center tertiary teaching hospital (University of São Paulo School of Medicine, Diagnostic Center of Department of Gastroenterology, Clinical Division, Gastroenterology Branch). Patients received colon preparation either at the hospital or at home, by means of four tablets of bisacodyl, taken orally, and a diet without residue (no fibers) on the day before the colonoscopy. On the day of the procedure, patients were given $500 \mathrm{~mL}$ (milliliter) of $20 \%$ mannitol solution and dimethicone orally.

A team of 19 physicians performed colonoscopies and the presence of two physicians during the colonoscopy was mandatory: the attending colonoscopist, responsible for the procedure, and one assistant. All colonoscopies were performed with ambient air, because the usage of carbon dioxide, although very common in laparoscopic procedures, is not standard in Brazil or our department.

Moderate and deep sedation were achieved by using midazolam and/or fentanyl, and propofol, respectively. The type of association and dosage given was at the discretion of the attending colonoscopist.

Relating to the equipment used, Olympus Optical videocolonoscopes were employed, including apparatus models CF-100 and CF-VL, image processor models CV-100 and CV-145 and light source models CLV-100 and CLV-160.

Data were collected from medical records of the Division of Medical Archives, the Diagnostic Center of the Department of Gastroenterology and the laboratory information system of the hospital. Collected data were age, gender, race, bowel preparation (inpatient or outpatient), morbidities, indications, findings and the complications of colonoscopy, bowel preparation, sedation and the procedure itself, both immediately and within 30 days after the procedure.

For the calculation of the Charlson index the variables according to figure 1 were considered. The index was then determined by adding the points for each present condition.
For the calculation of the CIRS-G a graduation was used, as indicated in the Manual of guidelines for scoring the cumulative for geriatrics (CIRS-G) for the 14 categories defined by anatomical sites. The total score according to figure 2 were calculated from these data.

\begin{tabular}{|c|c|}
\hline Condition & Score \\
\hline Myocardial infarction & 1 \\
\hline Congestive heart failure & 1 \\
\hline Peripheral vascular disease & 1 \\
\hline Cerebrovascular disease & 1 \\
\hline Dementia & 1 \\
\hline Chronic pulmonary disease & 1 \\
\hline Connective tissue disease & 1 \\
\hline Ulcer disease & 1 \\
\hline Mild liver disease & 1 \\
\hline Diabetes mellitus without end organ damage & 1 \\
\hline Hemiplegia & 2 \\
\hline Moderate to severe kidney disease & 2 \\
\hline Diabetes mellitus with end organ damage & 2 \\
\hline Tumor & 2 \\
\hline Leukemia & 2 \\
\hline Lymphoma & 2 \\
\hline Moderate to severe liver disease & 3 \\
\hline Metastatic solid tumor & 6 \\
\hline AIDS & 6 \\
\hline Total Score & Final Index \\
\hline 0 & 0 \\
\hline $1-2$ & 1 \\
\hline $3-4$ & 2 \\
\hline$\geq 5$ & 3 \\
\hline
\end{tabular}

FIGURE 1. The Charlson comorbidity index

\begin{tabular}{|ll|}
\hline \multicolumn{2}{|c|}{ Organs and systems (Value 0 - 4) } \\
Heart & Liver \\
Vascular & Renal \\
Hematopoietic & Genitourinary \\
Respiratory & Musculoskeletal/Integument \\
Eyes/ENT/Larynx & Neurological \\
Upper gastrointestinal & Endocrine/Metabolic \\
Lower gastrointestinal & Psychiatric illness
\end{tabular}

FIGURE 2. The cumulative illness rating scale for geriatrics (CIRS-G)

* Each system is rated as follows (value)

(0) No impairment to that organ/system

(1) Impairment does not interfere with normal activity; treatment may not be required

(2) Impairment interferes with normal activity; treatment is needed; prognosis is good

(3) Impairment is disabling; treatment is urgently needed; prognosis is guarded

(4) Impairment is life threatening 
For bowel preparation the complications considered were dehydration, electrolyte disturbance, nausea, vomiting, abdominal pain, hypoglycemia, hypervolemia, delirium, and acute renal failure defined, according to the specific Acute Kidney Injury Network - (AKIN) criteria, as an absolute increase in basal serum creatinine of more than or equal to $0.3 \mathrm{mg} / \mathrm{dL}$ or a percentage increase in basal serum creatinine of $50 \%$ or more). For sedation complications: drug induced respiratory depression with hypoxia and $\mathrm{CO}_{2}$ retention, aspirative pneumonia, cardiac arrhythmias, hypertension, hypotension and/or vasovagal fainting. For the colonoscopy procedure itself: bowel infection, bacteremia, perforation, abdominal pain and also delirium.

Data were analyzed by the SPSS 16.0 statistical program. For continuous variables and likelihood ratio tests the Student $t$ test was used and the Mann-Whitney test for categorical variables. The variables with $P<0.25$ were included in a multivariate analysis (Hosmer and Lemeshow test). In hypothesis testing the level of significance was 0.05 .

\section{RESULTS}

From January to December 2006, 207 patients aged 60 years and over, with an appropriate indication for colonoscopy according to the American Society for Gastrointestinal Endoscopy (ASGE) were included in the protocol. The mean age was 70.47 years and the cohort included $117(56.3 \%)$ women and 164 (78.8\%) Caucasians (Table 1); 90 (43.7\%) were outpatients, while $117(56.3 \%)$ were inpatients.

TABLE 1. Demographic data and characteristics of the population

\begin{tabular}{lc}
\hline Variable & $70.47 \pm 7.04$ \\
\hline Mean age (years) \pm DP & \\
Age range & $101(48.7 \%)$ \\
$\quad 60-69$ anos & $85(41.0 \%)$ \\
$70-79$ anos & $21(10.3 \%)$ \\
$\quad \geq 80$ anos & $117(56.3 \%)$ \\
Female & \\
Race & $164(79.3 \%)$ \\
$\quad$ Caucasian & $34(16.4 \%)$ \\
$\quad$ Black & $9(4.3 \%)$ \\
Oriental & \\
Charlson & $64(30.9 \%)$ \\
0 & $86(41.5 \%)$ \\
1 & $39(18.8 \%)$ \\
3 & $18(8.8 \%)$ \\
CIRS-G \pm DP & $6.29 \pm 3.06$ \\
N comorbidities & $3.49 \pm 2.0$ \\
\hline
\end{tabular}

The main indications were weight loss $(21.7 \%)$, bleeding $(20.3 \%)$ and anemia $(17.4 \%)$ (Table 2$)$ and the most important colonoscopy findings were diverticular disease $(43.5 \%)$ and polyps $(37.2 \%)$ (Table 3$)$.
TABLE 2. Indications for colonoscopy

\begin{tabular}{lcc}
\hline Indications & $\begin{array}{c}\text { No. of } \\
\text { indications }\end{array}$ & $\begin{array}{c}\% \text { of } \\
\text { patients }\end{array}$ \\
\hline Altered bowel habit & 15 & 7.2 \\
Iron deficiency anemia & 36 & 17.4 \\
Family history of colorectal cancer & 16 & 7.7 \\
Personal history of colorectal cancer & 10 & 4.9 \\
Decompression & 1 & 0.5 \\
Diarrhea <6 months & 20 & 9.7 \\
Diarrhea >6 months & 21 & 10.1 \\
Inflammatory bowel disease & 4 & 1.9 \\
Abdominal pain & 27 & 13 \\
Unintentional weight loss & 45 & 21.7 \\
Intestinal constipation & 22 & 10.6 \\
Screening for colorectal cancer & 1 & 0.5 \\
Image abnormalities & 7 & 3.4 \\
Rectal bleeding & 42 & 20.3 \\
Polyp surveillance & 22 & 10.7 \\
Other & 15 & 17.2 \\
\hline The patient could have more than one indication for colonoscopy
\end{tabular}

TABLE 3. Colonoscopic diagnosis

\begin{tabular}{lcc}
\hline Diagnosis & No. of diagnosis & \% of colonoscopies \\
\hline Angiodysplasia & 15 & 7.2 \\
Colorectal cancer & 20 & 9.7 \\
Extrinsic compression & 03 & 1.4 \\
Diverticula & 90 & 43.5 \\
Inflammatory & 06 & 2.9 \\
Operated & 07 & 3.4 \\
Polyps & 77 & 37.2 \\
Normal & 29 & 14 \\
Other & 16 & 7.7 \\
\hline
\end{tabular}

The patient could have more than one diagnosis

In this sample, $43(20.77 \%)$ patients had a colonoscopy complication: $1(0.48 \%)$ patient had a sedation complication (apnea and intubation), $4(1.93 \%)$ patients had problems related to the procedure (abdominal pain and bacteremia) and $38(18.35 \%)$ had complications related to the bowel preparation (Table 4).

TABLE 4. Bowel preparation colonoscopy complications

\begin{tabular}{lcc}
\hline Complications & $\begin{array}{c}\text { No. of } \\
\text { complications* }\end{array}$ & $\begin{array}{c}\% \text { of } \\
\text { colonoscopies }\end{array}$ \\
\hline Acute renal failure & 21 & $10.1 \%$ \\
Electrolyte disturbance & 13 & $6.28 \%$ \\
Vomiting & 8 & $3.8 \%$ \\
Abdominal pain & 6 & $2.89 \%$ \\
Dehydration & 5 & $2.41 \%$ \\
Nausea & 4 & $1.93 \%$ \\
Hypoglycemia & 2 & $0.9 \%$ \\
Delirium & 1 & $0.48 \%$ \\
Hypervolemia & 1 & $0.48 \%$ \\
\hline
\end{tabular}

* Some individuals had more than one complication (1.6 bowel preparation complications per patient) 
Patients who had complications were stratified according to their age and multimorbidity. In the 60-69 year age group, $15(14.85 \%)$ patients had some complication, $20(23.5 \%)$ in the $70-79$ year age group and $8(38.1 \%)$ in those of 80 years and older. The frequency of complications related to the Charlson index was $15.62 \%$ for score $0,18.6 \%$ for score 1 , $20.51 \%$ for score 2 and $50 \%$ for score 3 . The complications were statistically significant related to the group aged 80 and older $(P=0.037)$ and Charlson index $3(P=0.031)$. The CIRS-G index (figure 3), on the other hand, was not associated with complications $(P=0.25)$. Within comorbidities alone, the presence of heart failure, chronic kidney disease or dementia, was significantly associated with complications (Table 5).

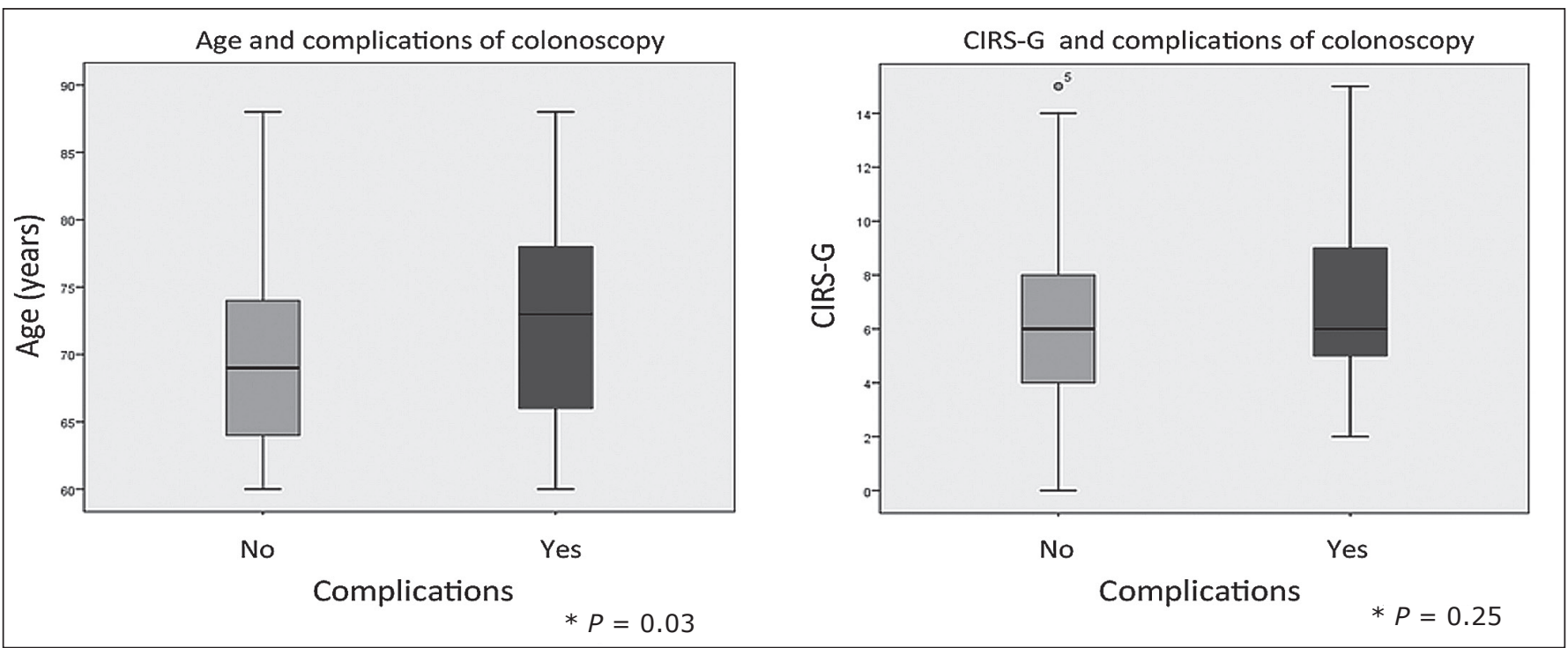

FIGURE 3. Correlation between complications, age and multimorbidity CIRS-G: cumulative illness rating scale for geriatrics

TABLE 5. Description of comorbidities and complications

\begin{tabular}{|c|c|c|c|}
\hline & With complication & No complication & $P$ \\
\hline Mean age (years) $\pm \mathrm{DP}$ & $72.47 \pm 7.4$ & $69.95 \pm 6.8$ & 0.03 \\
\hline N Comorbidities \pm DP & $3.81 \pm 2.23$ & $3.4 \pm 1.9$ & 0.24 \\
\hline CIRS-G & $6.77 \pm 3.0$ & $6.17 \pm 3.1$ & 0.25 \\
\hline \multicolumn{4}{|l|}{ Charlson } \\
\hline 0 & $10(23.3 \%)$ & $54(32.9 \%)$ & 0.534 \\
\hline 1 & $16(37.2 \%)$ & $70(42.7 \%)$ & 0.733 \\
\hline 2 & $8(18.6 \%)$ & $31(18.9 \%)$ & 0.469 \\
\hline 3 & $9(20.9 \%)$ & $9(5.5 \%)$ & 0.006 \\
\hline \multicolumn{4}{|l|}{ Comorbidity } \\
\hline $\mathrm{CHF}$ & $9(20.9 \%)$ & $12(7.3 \%)$ & 0.008 \\
\hline CI & $6(14 \%)$ & $14(8.5 \%)$ & 0.28 \\
\hline CKD & $10(23.3 \%)$ & $6(3.7 \%)$ & 0.00 \\
\hline COPD & $1(2.3 \%)$ & $5(3.0 \%)$ & 0.80 \\
\hline Diabetes & $14(32.6 \%)$ & $37(22.6 \%)$ & 0.17 \\
\hline Tumor & $13(30.2 \%)$ & $44(26.8 \%)$ & 0.65 \\
\hline CVD & $2(4.7 \%)$ & $7(4.3 \%)$ & 0.91 \\
\hline Hypertension & $27(62.8 \%)$ & $78(47.6 \%)$ & 0.07 \\
\hline Dementia & $2(4.7 \%)$ & $0(0 \%)$ & 0.006 \\
\hline
\end{tabular}

CIRS-G: cumulative illness rating scale for geriatrics. CHF: congestive heart failure; CI: coronary insufficiency; CKD: chronic kidney disease; COPD: chronic obstructive pulmonary disease; CVD: cerebrovascular disease. 
After adjustment for the multiple logistic regression model, age and the Charlson index were related both to complications in colonoscopy and in bowel preparation. Individuals aged 80 years and older had an RR $=3.4(1,2-$ $10,1), P=0.025$ and those with a Charlson index 3 had an $\mathrm{RR}=5.2(1,6-16,8), P=0.006$.

The Charlson index also showed a positive association with the onset of acute renal failure due to bowel preparation. A Charlson score 1 had an $\mathrm{RR}=9.49(1.1,80.3)$, $P=0.04$, a Charlson score 2 had an RR $=13.8(1.4,135.5)$, $P=0.024$ and a Charlson score 3 had an $\mathrm{RR}=35.3(3.2$, 392.7), $P=0.004$ for acute renal failure.

\section{DISCUSSION}

The patients in this study had appropriate colonoscopy indications according to the American and European Gastrointestinal Endoscopy Societies ${ }^{(17,19)}$. Endoscopic findings, including colorectal cancer, were similar to those previously reported ${ }^{(1)}$.

The colonoscopy complication rates in the elderly are variable in the literature, from $0.9 \%$ to $16.6 \%$, but comparison is difficult because most data are retrospective and includes little information about complications within 30 days after the procedure ${ }^{(6)}$. Zubarik et al. conducted a prospective study of complications within 30 days of a colonoscopy and observed a complication rate of $16.6 \%{ }^{(24)}$.

The higher rate of complications within 30 days of the exam $(20,77 \%)$ observed in this present study could be explained by actively searching for clinical and laboratory data which is not performed in other studies, the high complexity of the patients and feasibly because of the use of mannitol as the solution for preparing the exam. The present study also found a low complication rate due to sedation and the procedure, as in the literature, and no major complications (death, bleeding and perforation). The majority of complications were related to the bowel preparation (18.35\%).

The American and European Gastrointestinal Endoscopy Societies in its guidelines suggest a higher frequency of complications in patients with significant multimorbidity, especially heart failure, hypertension and renal failure ${ }^{(5,11)}$. The Food and Drug Administration (FDA) advises taking electrolytes, creatinine and urea samples before and after the procedure, especially in higher risk patients ${ }^{(3)}$.

On the other hand, multimorbidity scales have been proven to be useful in identifying subgroups of the elderly more susceptible to treatment complications. In other studies the Charlson Index particularly demonstrated a good prognostic power for mortality and surgical complications in patients with colorectal cancer $^{(8)}$. Despite the fact that Perry et al. recommended, in a study conducted in 1989 , that patients with multimorbidity should be hospitalized for colonoscopy ${ }^{(18)}$, another study published in 1992 by Waye et al., analyzing 2,097 patients undergoing colonoscopy on an outpatient basis, demonstrated the safety of the procedure under these conditions, even in elderly patients with associated diseases ${ }^{(22)}$.

The present study showed a significant association $(P=0.037)$ between age and complications, with an increased risk for the group of 80 years and older. The multimorbidity also showed significant correlation with complications when assessed by the Charlson index $(P=0.031)$ and a score of 3 was associated with a higher number of complications. Among the morbidities alone, the presence of heart failure $(P=0.008)$, chronic kidney disease $(P=0.00)$ and dementia $(P=0.006)$ were also significantly associated with complications.

This study has some limitations. It is a retrospective study with a relatively small sample, the varied degree of skill wielded by the colonoscopists, the inclusion of outpatients and inpatients undergoing colorectal surgery and the heterogeneity of the sedative drugs made the sample more heterogeneous, albeit more representative of clinical practice.

The present study findings confirm what is known today as grade D Evidence recommendation: that knowing the potential complications and their expected frequency according to the particularities of the patient can improve the outcome of complications and promote steps to minimize risks ${ }^{(5)}$.

\section{CONCLUSIONS}

Very elderly patients ( 80 years and older) and the Charlson multimorbidity index 3 were significantly correlated with colonoscopy complications. The CIRS-G was not a good predictor of risk in this sample.

The rate of complications within 30 days of the examination was $20.77 \%$, most of them $(18.35 \%)$ were related to the preparation. This study showed a low rate of complications related to sedation and procedure, similar to the literature, and no major complications (death, bleeding and perforation).

\section{ACKNOWLEDGEMENTS}

We are grateful to Marcel Hiratsuka, Luciana Pricoli Vilela, Vivian M Ussui and Flair Jose Carrilho for providing their clinical and research support. We are grateful to the Nurse Division of the University of São Paulo Faculty of Medicine Clinics Hospital for special dedication to patient care during all steps of the colonoscopic examination.

The Human Ethics Committee of the University of São Paulo Faculty of Medicine Clinics Hospital (CAPPesq 0538/08) has approved this study. 
Stein FC, Hojaij NHSL, Silva JGN, Borges LV, Jacob-Filho W, Hashimoto CL. Complicações de colonoscopia em idosos: impacto da multimorbidade e idade. Arq Gastroenterol. 2013,50(4):251-6.

RESUMO - Contexto - A idade tem sido considerada um fator de risco independente para complicações colonoscópicas, especialmente na presença de multimorbidade. Objetivos - O objetivo primário foi verificar a correlação entre idade, multimorbidade e complicações colonoscópicas em idosos. Métodos - Coorte retrospectiva de pacientes com 60 anos ou mais submetidos a colonoscopia. Foram coletados idade, multimorbidade (de acordo com os índices cumulative illness scale for geriatrics e Charlson) e complicações relacionadas ao preparo e procedimento (sedação e exame). Resultado - Dos 207 pacientes (idade média $70.47 \pm 7.04$ ) com indicação apropriada para colonoscopia segundo a Sociedade Americana de Endoscopia Gastrointestinal, 43 (20.77\%) tiveram alguma complicação: 1 (0.48\%) com complicação pela sedação (apneia), 4 (1.93\%) relacionada ao procedimento (dor abdominal e bacteremia) e 38 (18.35\%) pelo preparo (insuficiência renal aguda, hipotensão). Pacientes $\geq 80$ anos tiveram RR = 3.4 (1.2-10.1), $P=0.025$, para complicações e aqueles com índice de Charlson 3, um $\mathrm{RR}=5.2(1.6-16.8), P=0.006$. Cumulative illness rating scale for geriatrics, não mostrou associação com complicações $(P=0.45)$. Conclusão - Houve risco significativo de complicação em muito idosos ( $\geq 80$ years) e no grupo com índice de Charlson 3. Cumulative illness rating scale for geriatrics não se mostrou um bom preditor de risco nesta amostra.

DESCRITORES - Colonoscopia, efeitos adversos. Idoso. Morbidade.

\section{REFERENCES}

1. Arora A, Singh P. Colonoscopy in patients 80 years of age and older is safe, with high success rate and diagnostic yield. Gastrointest Endosc. 2004;60:408-13.

2. Charlson ME, Pompei P, Ales KL, MacKenzie CR. A new method of classifying prognostic comorbidity in longitudinal studies: Development and validation. J Chronic Dis .1987;40:373-83.

3. Curran MP, Plosker GL. Oral sodium phosphate solution. A review of its use as a colorectal cleanser. Drugs 2004;64:1697-714.

4. de Groot V, Beckerman H, Lankhorst GJ, Bouter LM. How to measure comorbidity: a critical review of available methods. J Clin Epidemiol. 2003;56:221-29.

5. Dominitz JA, Eisen GM, Baron TH, Goldstein JL, Hirota WK, Jacobson BC, Johanson JF, Leighton JA, Mallery JS, Raddawi HM, Vargo JJ 2nd, Waring JP, Fanelli RD, Wheeler-Harbough J, Faigel DO; Standards of Practice Committee. American Society for Gastrointestinal Endoscopy. Complications of colonoscopy. Gastrointest Endosc. 2003;57:441-45.

6. Epstein O. British Society of Gastroenterology. Guidelines in Gastroenterology. 2006;14-19.

7. Extermann M. Measurement and impact of comorbidity in older cancer patients. Crit Rev Oncol Hematol. 2000;35:181-200.

8. Feinstein A. Clinical Judgment. New York: The Williams \& Wilkins Company. 1967.

9. Hall WH, Ramachandran R, Narayan S, Jani AB, Vijayakumar S. An electronic application for rapidly calculating Charlson comorbidity score. BMC Cancer 2004;4:94-101.

10. INCA. Estimativas 2008: Incidência de Câncer no Brasil. Rio de Janeiro: Esdeva; 2008. Available from: http://www.inca.gov.br/estimativa/2008/versaofinal.pdf.

11. Lagares-Garcia JA, Kurek S, Collier B, Diaz F, Schilli R, Richey J, Moore RA. Colonoscopy in octogenarians and older patients. Surg Endosc. 2001;15:262-5.

12. Levin TR, Zhao W, Conell C, Seeff LC, Manninen DL, Shapiro JA, Schulman J. Complications of colonoscopy in an integrated health care delivery system. Ann Inter Med. 2006;145:880-6.

13. Lieberman DA, Weiss DG, Bond JH, Ahnen DJ, Garewal H. Use of colonoscopy to screen asymptomatic adults for colorectal cancer. Veterans affairs cooperative study group 380. N Engl J Med. 2000;343:162-8.
14. Linn BS, Linn MW, Gurel L. Cumulative Illness Rating Scale. J Am Geriatr Soc 1968,16:622-626.

15. Macrae FA, Tan KG, Williams CB. Towards safer colonoscopy: a report on the complications of 5000 diagnostic or therapeutic colonoscopies. Gut. 1983;24: 376-83.

16. Miller EA, Towers A. A manual of guidelines for scoring the cumulative illness rating scale for geriatrics (CIRS-G). University of Pittsburgh; 1991.

17. Minoli G, Meucci G, Bortoli A, Garripoli A, Gullotta R, Leo P, Pera A, Prada A Rocca F, Zambelli A. The ASGE guidelines for the appropriate use of colonoscopy in an open access system. Gastrointest Endosc. 2000;52:39-44.

18. Perry RE, Christensen JB, Christensen MA, Thorson AG. Office colonoscopy - a safe procedure in selected patients. Dis Colon Rectum. 1989;32:1031-3.

19. Rex DK, Petrini JL, Baron TH, Chak A, Cohen J, Deal SE, Hoffman B, Jacobson BC, Mergener K, Petersen BT, Safdi MA, Faigel DO, Pike IM; ASGE/ACG Taskforce on Quality in Endoscopy. Quality indicators for colonoscopy. Am J Gastroenterol. 2006;101:873-885.

20. Schroy P. Polyps, adenocarcinomas, and other intestinal tumors. In: Cohen S, Wolfe MM. Therapy of digestive disorders: a companion to Sleisenger and Fordtran's gastrointestinal and liver disease. Philadelphia: Saunders. 2000;645-73.

21. van den Akker M, Buntinx F, Metsemakers JF, Roos S, Knottnerus JA. Multimorbidity on general practice: prevalence, incidence, and determinants of co-occurring chronic and recurrent disease. J Clin Epidemiol. 1998;51:367-75.

22. Waye JD, Lewis BS, Yessavan S. Colonoscopy: a prospective report of complications. J Clin Gastroenterol. 1992;15:247-51.

23. Zauber AG, Winawer SJ, O'Brien MJ, Lansdorp-Vogelaar I, vanBallegooijen M, Hankey BF, Shi W, Bond JH, Schapiro M, Panish JF, Stewart ET, Waye JD. Colonoscopy polypectomy and long-term Prevention of colorectal-cancer deaths. N Engl J Med. 2012;366:687-96.

24. Zubarik R, Fleischer DE, Mastropietro C, Lopez J, Carrol J, Benjamin S, Eisen G. Prospective analysis of complications 30 days after outpatient colonoscopy Gastrointest Endosc. 1999;50:322-8. 